\title{
PRÁTICAS DE GESTÃO AMBIENTAL E PRODUÇÃO MAIS LIMPA: UMA ANÁLISE DO PROCESSO PRODUTIVO DA CACHAÇA SANHAÇU
}

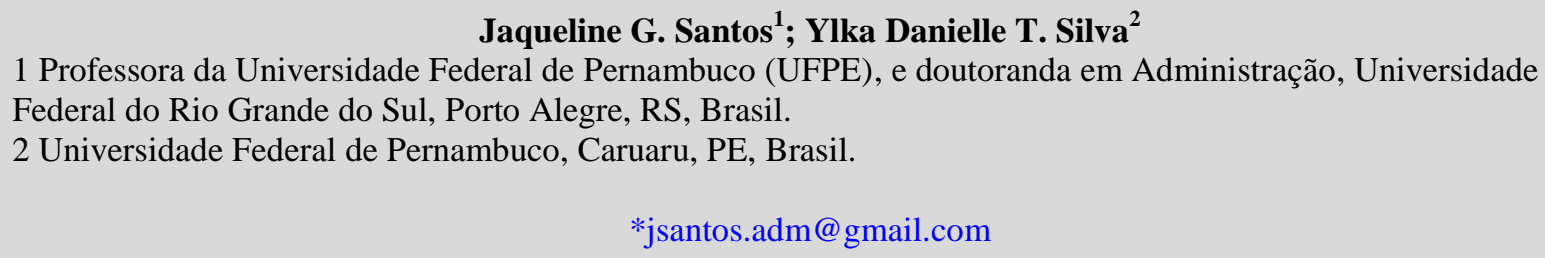

*jsantos.adm@gmail.com

\section{RESUMO}

Diante dos impactos ambientais gerados pelas atividades produtivos, algumas empresas têm adotado programas que buscam minimizar os efeitos negativos ao meio ambiente e ao mesmo tempo produzir produtos de qualidade e menos degradantes ao ambiente natural e as pessoas, dentre estes se destaca a Produção mais Limpa $(\mathrm{P}+\mathrm{L})$. Assim, o presente trabalho tem como objetivo analisar as práticas de produção mais limpa adotadas pela cachaçaria Sanhaçu no seu processo produtivo. O estudo se trata de uma pesquisa exploratória e descritiva, que teve como coleta de dados a entrevista semiestruturada e observação não participante a partir de várias visitas a empresa estudada, além da análise de dados secundários. Os resultados apontam que a Sanhaçu apresenta estratégias de produção mais limpa, além de práticas de gestão ambiental o que tem contribuído para a empresa receber vários prêmios importantes e ser considerada a primeira cachaça orgânica certificada de Pernambuco.

PALAVRAS-CHAVE: Gestão Ambiental, Produção mais Limpa, Cachaça, Produto Orgânico.

\section{ENVIRONMENTAL MANAGEMENT AND CLEANER PRODUCTION PRACTICES: AN ANAL YSIS OF THE PRODUCTION PROCESS OF CACHAÇA SANHAÇU}

\begin{abstract}
Given the environmental impacts generated by productive activities, some companies have adopted programs that seek to minimize negative effects on the environment and at the same time produce quality products that are less degrading to the natural environment and people, among which the Cleaner Production. Thus, the present work aims to analyze the cleaner production practices adopted by the cachaçaria Sanhaçu in its production process. The study is an exploratory and descriptive research, which had as data
\end{abstract}

collection the semi-structured interview and nonparticipant observation from several visits to the company studied, in addition to the analysis of secondary data. The results indicate that Sanhaçu presents cleaner production strategies, as well as environmental management practices, which has contributed to the company receiving several important awards and being considered the first certified organic cachaça from Pernambuco.

KEYWORDS: Environmental Management, Cleaner Production, Cachaça, Organic Product. 


\section{INTRODUÇÃO}

Os impactos ambientais gerados pelas atividades industriais evidenciam um grande potencial de comprometimento da qualidade de vida do homem, desastres, destruição e contaminação do meio ambiente (SEIFFERT, 2010). Por isso, é cada vez comum às empresas preocuparem-se com a introdução da gestão ambiental em suas atividades, quer seja para atendimento das pressões dos diversos stakeholders ou mesmo por uma questão de marketing e diferencial competitivo. A mudança de atitude frente à adoção de práticas de gestão ambiental se deve, em grande parte, ao reconhecimento do valor da comercialização de uma filosofia "ambiental" (JABBOUR, 2010).

Assim, a gestão ambiental ganha espaço nas estratégias organizacionais, sendo o desafio dos gestores desenvolverem metas e ações que visem à minimização ou eliminação dos impactos negativos causados ao meio ambiente em decorrência de suas atividades produtivas. Para tanto, as empresas devem buscar preservar os recursos naturais utilizando matérias primas ecologicamente corretas, minimizar a geração de resíduos gerados nos seus processos, além de integrar todos os setores da empresa, de modo a transformasse em uma cultura organizacional baseada nas práticas de gestão ambiental. Sabe-se que um modelo de negócio sustentável alinha os interesses de todos, e explicitamente considera o meio ambiente e a sociedade como as principais partes interessadas (BOCKEN et al., 2014). O desafio está em projetar modelos ou utilizar ferramentas que permitam captar valor econômico para si, através da obtenção de benefícios sociais e ambientais ao mesmo tempo (SCHALTEGGER; LÜDEKE-FREUND; HANSEN, 2012).

Nesse sentido, destaca-se, neste estudo, que uma das formas das empresas contribuírem e se posicionarem frente às preocupações ambientais é a partir da introdução da Produção mais Limpa (SANTOS; CARNEIRO; RAMALHO, 2015; BARBIERI, 2016; SILVA, et al., 2017). A P+L é uma "abordagem contínua de uma estratégia ambiental preventiva e integral que envolve processos, produtos e serviços, de maneira que se previna ou reduzam os riscos de curto e longo prazo tanto para o ser humano e o meio ambiente" (DIAS, 2011, p.145). Yusup et al. (2014) destaca que a implementação da $\mathrm{P}+\mathrm{L}$ reduz os custos de conservação e cuidado ambiental, melhora a eficiência do uso de recursos, promove práticas saudáveis em prol do meio ambiente, e minimiza o desperdício de materiais, além de contribuir para a produção de produtos menos degradantes ao meio ambiente.

Segundo o Conselho Nacional de Tecnologias Limpas - CNTL (2003, p.7) a P+L "é uma estratégia econômica, ambiental e tecnológica integrada aos processos e produtos, a fim de aumentar a eficiência no uso de matéria prima, água e energia, através da não geração, minimização ou reciclagem de resíduos gerados em um processo produtivo", visto que os resíduos geram custo para a organização, seja consumindo insumos ou em forma de custo de tratamento e armazenagem ou até mesmo em forma de multas quando não são tratados. Essencialmente, a intenção da $\mathrm{P}+\mathrm{L}$ é minimizar desperdícios e emissões pela eliminação de suas causas já na criação de produtos e serviços, em vez de tratá-los depois que estes foram criados (VAN BERKEL, 2007).

Compreende-se, portanto, a $\mathrm{P}+\mathrm{L}$ como uma abordagem que busca a ecoeficiência no uso dos recursos, o controle na fonte, a não geração dos resíduos e o princípio da precaução (Greenpeace, 2001), agindo de forma proativa quanto à questão ambiental. Partindo desta premissa, realizou, por meio de um estudo empírico, uma pesquisa em uma empresa do setor sucroalcooleiro do estado de Pernambuco, a cachaçaria Sanhaçu. A cachaça é uma bebida genuinamente brasileira, este produto teve sua legitimidade atestada através da Lei $\mathrm{n}^{\circ}$ 8.918, de 14 de julho de 1994, que dispõe sobre a padronização, classificação, registro, inspeção, produção e a fiscalização de bebidas, e complementada pelo Decreto nº 4.072/ 2002 (BRASIL, 2002). 
A produtora de cachaça orgânica Sanhaçu, é uma empresa que tem preocupações com a gestão ambiental, tem-se como problema de pesquisa: Quais as práticas de produção mais limpa que são adotadas pela cachaçaria Sanhaçu no seu processo produtivo? Assim, o objetivo geral foi o de analisar as práticas de produção mais limpa que são adotadas pela cachaçaria Sanhaçu no seu processo produtivo. Para tanto, foi realizada uma pesquisa de abordagem qualitativa, com coleta de dados a partir de entrevistas semiestruturadas envolvendo a diretora/sócia da Sanhaçu, além de dois colaboradores da empresa, dados secundários, além da observação direta não participante registrada em nota pela pesquisadora.

Além desta introdutória, este estudo está dividido em quatro seções. Na primeira seção, é realizada uma revisão de literatura e, em seguida, são explicitados os procedimentos metodológicos desta pesquisa. A quarta seção mostra a análise e discussão dos resultados obtidos e, por fim, a quinta seção contempla as considerações finais.

\section{MATERIAIS E MÉTODOS}

Com vistas a atender ao objetivo de analisar as práticas de produção mais limpa que são adotadas pela cachaçaria Sanhaçu no seu processo produtivo, esta pesquisa possui uma abordagem qualitativa. Esta abordagem permite que um fenômeno seja mais bem compreendido no contexto em que ocorre e do qual é parte, analisado numa perspectiva integrada (CRESWELL, 2010). Para Denzin e Lincoln (2006, p.3) a pesquisa qualitativa é uma atividade situada que posiciona o observador no mundo. Ela consiste em um conjunto de práticas interpretativas e materiais que tornam o mundo visível [...] logo os pesquisadores estudam as coisas em seus contextos naturais, deste modo tentam entender ou interpretar os fenômenos de acordo com as percepções que as pessoas lhe atribuem.

Para a operacionalização da pesquisa foi feita inicialmente uma pesquisa bibliográfica para levantamento de material - artigos, livros e jornais, etc. - para melhor familiaridade sobre o tema, o que possibilitou a construção da revisão de literatura que embasou a elaboração do roteiro para as entrevistas. O método adotado foi o estudo de caso, que é uma investigação empírica que pesquisa um fenômeno contemporâneo de maneira profunda em seu contexto, quando os limites entre o fenômeno e o contexto não estão claramente definidos (YIN, 2015). Assim, a seleção do caso estudado considerou o interesse da empresa na introdução de práticas de produção mais limpa. Nesse sentido, foi selecionada a Cachaçaria Sanhaçu que tem sua unidade produtiva na Zona da Mata Sul de Pernambuco. O contato inicial com a empresa se deu em 2015 a partir de uma visita técnica a fábrica, momento que foi explicado o objetivo da pesquisa. Após esse primeiro contato foi acordado novos encontros para a fase de coleta de dados que concluiu em junho de 2016.

A coleta de dados se deu em duas etapas. A primeira foi para reconhecimento do objeto estudado a partir, principalmente, da observação direta não participante realizada durante uma visita técnica a fábrica que durou aproximadamente duas horas. A segunda etapa compreendeu a realização de entrevistas individuais semiestruturadas com a sócia-proprietária e dois funcionários da empresa. Para Gaskell (2004) a entrevista é uma interação que se dá em determinado contexto, entre duas pessoas - o entrevistador e o entrevistado - e que, de algum modo, é dirigida pelo primeiro.

As entrevistas duraram em média duas horas (cada entrevista foi registrada através de gravação em áudio e, posteriormente, transcrita) e as observações diretas não participantes foram registradas em notas e fotografias feitas pela pesquisadora no momento de visita a fábrica, além de dados secundários coletados (website da empresa, informativos publicados pela empresa em jornais 
e redes sociais). Salienta-se que a coleta de se deu a partir de um roteiro com questões elaboradas com base na revisão de literatura apresentada na seção antecedente.

Para análise dos dados coletados foi utilizada a técnica análise de conteúdo, a qual compreende um conjunto de técnicas de análise de comunicação, que utiliza procedimentos sistemáticos e objetivos de descrição do conteúdo das mensagens (FREITAS; JANISSEK, 2000; BARDIN, 2011). Para um melhor entendimento da sequência das etapas realizadas, segue a Figura 1 que compreende o desenho de pesquisa.

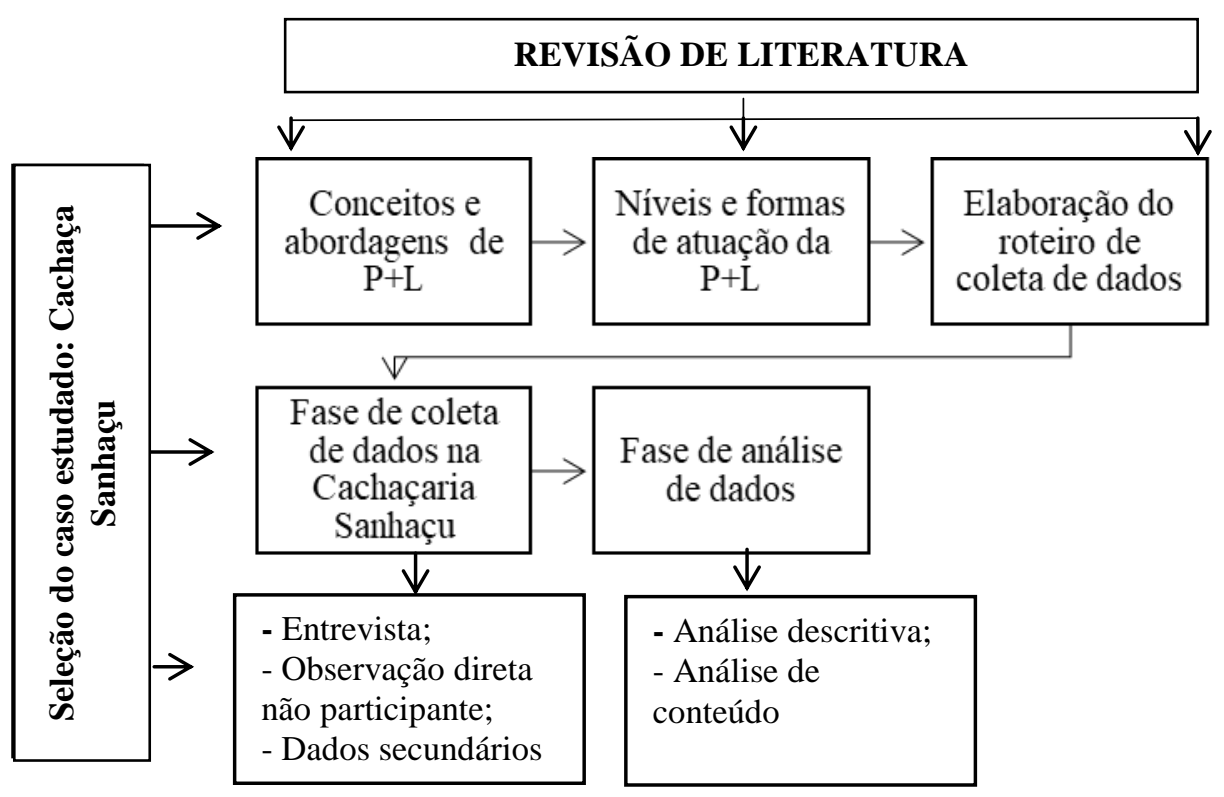

Figura 1 - Desenho da pesquisa. Fonte: Elaborada pelas autoras (2017).

Com base na Figura 04, observam-se as etapas realizadas para a realização desta pesquisa, iniciando com a pesquisa bibliográfica a partir do levantamento de material sobre o tema até a fase de análise dos dados coletados na cachaçaria Sanhaçu. A seguir tais dados são analisados para atendimento do objetivo proposto.

\section{REVISÃO DE LITERATURA}

É apresentada nesta seção a revisão da literatura basilar sobre os constructos que fundamentaram este estudo. Inicialmente é feita uma discussão sobre gestão ambiental e a produção mais limpa e, em seguida, abordam-se sobre os diferentes níveis de atuação da P+L.

\subsection{Gestão Ambiental e a Produção Mais Limpa}

Desde a década de 70 houve diversos encontros internacionais para debater sobre os impactos ambientais decorrentes da produção industrial pelo uso consumo irresponsável dos recursos naturais. Um dos primeiros encontros internacionais que uniu diferentes países com pauta comum de discussão foi a Conferência de Estocolmo em 1972. Diversos encontros foram realizados 
ao longo do tempo, o mais recente aconteceu em 2015. A Cúpula das Nações Unidas sobre o Desenvolvimento Sustentável se reuniu na sede da Organização das Nações Unidas (ONU) em Nova Iorque, oportunidade que foi apresentada a agenda 2030, sendo um dos objetivos: "melhorar progressivamente, até 2030, a eficiência dos recursos globais no consumo e na produção, e empenhar-se para dissociar o crescimento econômico da degradação ambiental" (AGENDA 2030, 2015).

Para tanto, observa-se a necessidade das empresas se preocuparem com os efeitos negativos que causam ao meio ambiente, além da indigência em utilizar com responsabilidade os recursos naturais. Batista, Giesta e Leite (2013) consideram que as atividades industriais são as que mais causam impactos ao meio ambiente, por isso a abordagem ambiental vem crescendo nas empresas, uma vez que a sociedade tende a pressioná-las ou mesmo as legislações obrigam a tomada de algumas iniciativas em prol à redução dos impactos ao meio ambiente.

Uma das formas das empresas se alinharem aos preceitos da gestão ambiental é a partir da introdução de um Sistema de Gestão Ambiental (SGA), o qual foi definido pela Norma Brasileira (NBR) ISO 14001, "como parte do sistema de gestão que compreende a estrutura organizacional, as responsabilidades, as práticas, os procedimentos, os processos e recursos para aplicar, elaborar, revisar e manter a política ambiental da empresa" (PEIXE et al., 2011, p. 3). Para aplicar o SGA, o gestor deve desenvolver medidas que visem à prevenção a danos ambientais, a economia de insumos, a redução de desperdícios e o desenvolvimento de novas tecnologias (SANTOS; CARNEIRO; RAMALHO, 2015).

Nesse sentido, tem-se a produção mais limpa, a qual consiste em uma abordagem compreensiva e preventiva que diminuem os impactos da produção ao meio ambiente (CNTL, 2003). Para Glavic e Lukman (2007), a P+L inclui tanto uma condição para atingir melhorias ambientais no processo e desenvolvimento de produtos quanto uma contribuição para uma maior sustentabilidade, além da possibilidade do aumenta o nível de competitividade através do aumento de receitas e redução do desperdício, produzindo um produto ambientalmente correto (SILVA, et al., 2017).

A United Nations Environment Programme (UNEP), a partir do Programa das Nações Unidas para o Meio Ambiente (PNUMA), define a produção mais limpa como a aplicação contínua de uma estratégia ambiental preventiva integrada aos processos, produtos e serviços para aumentar a eficiência global, e reduzir os riscos para os seres humanos e o meio ambiente (UNEP, 2006). Produção mais limpa pode ser aplicada aos processos utilizados em qualquer indústria, produtos em si e aos diversos serviços prestados na sociedade. Sua aplicação contínua visa à integração da prevenção ambiental, estratégia de processos, produtos e serviços para aumentar a eficiência e reduzir os riscos para os seres humanos e o meio ambiente (VAN BERKEL, 2007). Para tanto, obedece a uma hierarquia de ações, na qual são possíveis modificações em vários níveis de atuação e diferentes estratégias de aplicação (CNTL, 2003), conforme é discutido na seção a seguir.

\subsection{Níveis de atuação da Produção mais Limpa e a Produção da Cachaça}

A Produção mais Limpa segue a seguinte hierarquia de prioridade: Prevenção; redução > reuso e reciclagem $>$ Tratamento com recuperação de materiais e energias $>$ tratamento e disposição final. A P+L consiste em ações que estão voltadas para conservar o meio ambiente, por meio da conservação das matérias-primas, energia e redução da poluição. Além disso, o programa de $\mathrm{P}+\mathrm{L}$ requer também mudanças e inovações na gestão da empresa, nos colaboradores, em aspectos 
políticos e tecnológicos (MELO, et al., 2012). A Figura 2 apresenta as mudanças necessárias para implantação da $\mathrm{P}+\mathrm{L}$ e suas várias formas de atuação.

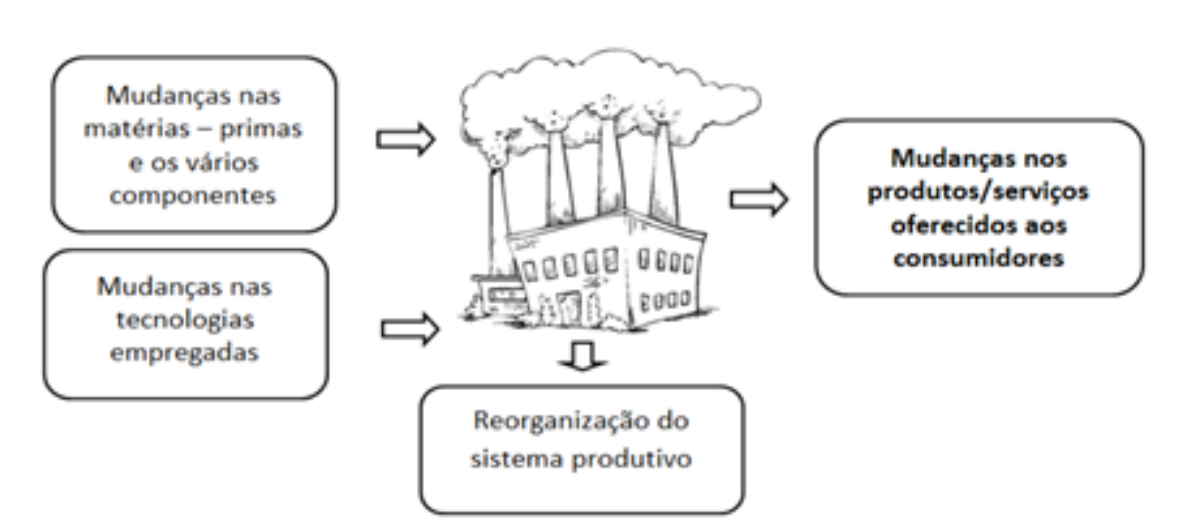

Figura 2 - Formas de atuação da P+L.

Fonte: Santos, Carneiro e Ramalho (2015, pág. 42).

Com base na Figura 2, observa-se que a implantação da $\mathrm{P}+\mathrm{L}$ requer diversas mudanças no processo produtivo, no que tange a mudanças nas matérias-primas e os vários componentes, a $\mathrm{P}+\mathrm{L}$ age na eliminação ou redução de materiais tóxicos ou ecologicamente prejudiciais, na purificação do material de entrada do processo e na prevenção da geração de resíduos poluentes. Quanto a mudanças na tecnologia, procuram adaptarem-se os equipamentos e os processos, com o objetivo de reduzir e/ou eliminar a geração de resíduos, e ainda reutilizar resíduos da produção como matéria prima no processo original ou em outros processos. As mudanças no produto/serviço oferecidos aos consumidores procuram alterar a composição, a durabilidade e os padrões de qualidade do produto e o emprego de produtos substitutos (SANTANA, 2009). Por sua vez, Yong et al. (2016) chamam atenção que as organizações precisam estar cientes de que, por ser uma técnica de aplicação contínua, a $\mathrm{P}+\mathrm{L}$ mobilizará toda a organização, provocando mudanças culturais em todos os seus níveis hierárquicos, ou seja, os colaboradores precisam passar por um processo de aprendizagem organizacional, para além de aprender as novas técnicas de $\mathrm{P}+\mathrm{L}$, compreender a importância da ferramenta para a empresa e seus interessados.

As mudanças supracitadas geram custos para as empresas, no entanto, em contrapartida a empresa adota uma abordagem preventiva, focando o potencial de ganhos do processo produtivo por meio de uma análise de desperdícios. Dessa forma, a produção ganha em otimização e melhorias nos seus processos (PIMENTA; GOUVINHA, 2012). Assim, as oportunidades de melhoria baseadas na $\mathrm{P}+\mathrm{L}$ podem ser desenvolvidas em três níveis, $\quad$ quais sejam: nível 1 redução na fonte; nível 2 - reciclagem interna e nível 3 - reciclagem externa (CNTL, 2003) como pode ser visualizado na Figura 3 abaixo. 


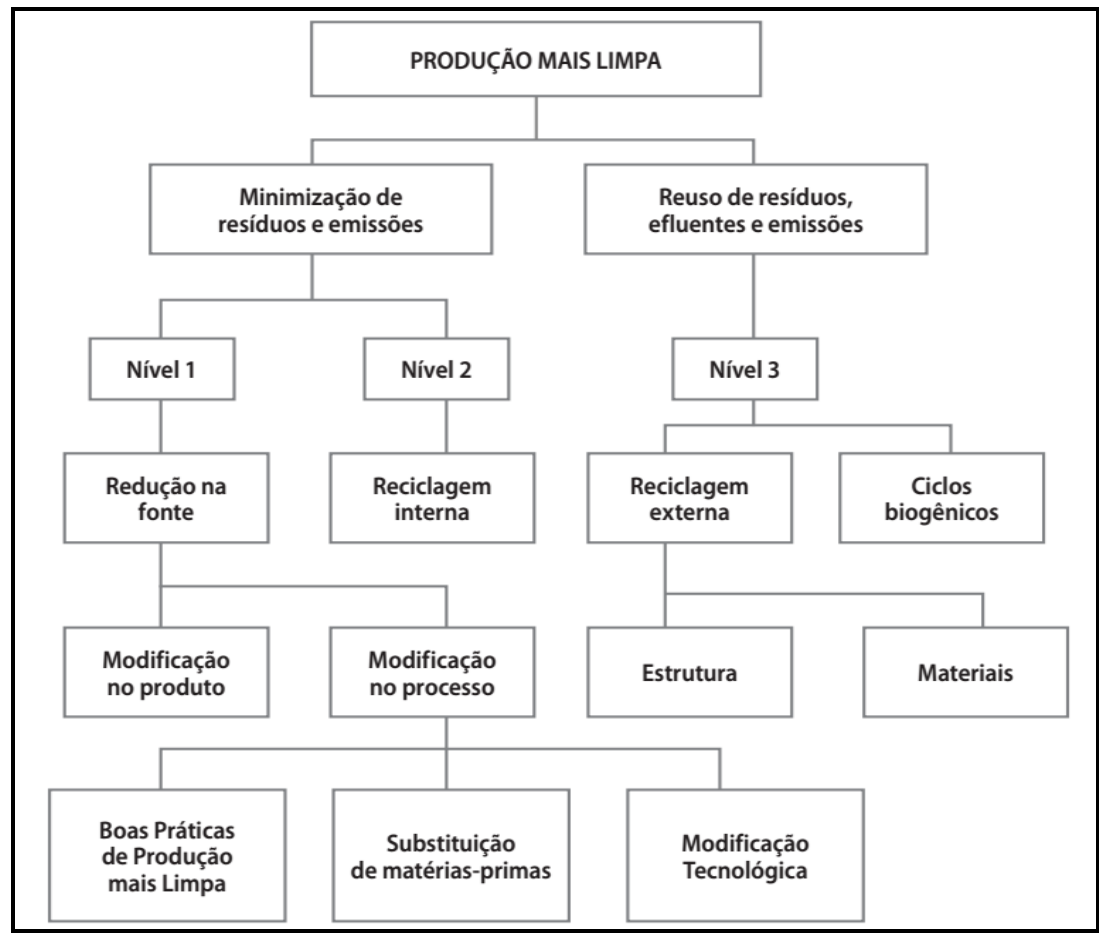

Figura 3 - Níveis de oportunidade de melhoria baseadas na produção mais limpa. Fonte: Centro Nacional de Tecnologias Limpas (2003).

Como observado na Figura 3, os níveis de oportunidades de melhoria baseada na produção mais limpa se dar em duas vias e três níveis. A minimização de resíduos e emissões compreende o primeiro nível, o qual é marcado pela redução na fonte, através de medidas que visam otimizar o uso de recursos e evitar a geração de poluentes, via modificação no produto ou modificação no processo (boas práticas de $\mathrm{P}+\mathrm{L}$, mudanças em matérias-primas e modificação tecnológica). Os poluentes que não podem ser evitados devem ser reintegrados ao processo de produção da empresa que compreende o segundo nível (reciclagem interna). Somente após a busca por soluções de eliminação ou redução na fonte e de reciclagem interna é que se deve optar por medidas de reciclagem de resíduos e efluentes fora da empresa, compreendendo o terceiro nível (CNTL, 2003; VENANZI; MORIS, 2013).

As empresas que aderem ao programa de Produção mais Limpa tem como benefícios a melhoria da competitividade, através da redução uso de materiais e energias, a redução de encargos ambientais e melhoria do produto e das condições de trabalho para os funcionários (MAGNAGO, 2013). O CNTL aponta algumas vantagens da $\mathrm{P}+\mathrm{L}$ quando comparada a tecnologias fim-de-tubo, quais sejam: [1] redução da quantidade de materiais e energia utilizados, [2] exploração do processo produtivo com a minimização de resíduos e emissões, [3] o processo produtivo é visto como um todo, [4] caminho para um desenvolvimento sustentável (CNTL, 2003).

Tem-se que a $\mathrm{P}+\mathrm{L}$ pode ser aplicada em todos os tipos de empresas, quer sejam indústrias ou empresas de serviços. Neste estudo o foco de análise é uma cachaçaria. A legislação Brasileira vigente define a cachaça como:

Denominação típica e exclusiva da aguardente de cana produzida no Brasil, com graduação alcoólica de 38 a $48 \%$ em volume, a $20^{\circ} \mathrm{C}$, obtida pela destilação do mosto fermentado de cana-de-açúcar, com características sensoriais peculiares, podendo ser adicionada de açúcares até seis gramas por litro, expressos em sacarose (BRASIL, 2009, Art. 53). 
Em 2012 após acordo firmado entre Brasil e Estados Unidos, a cachaça passou a ser reconhecida como um produto exclusivo e genuinamente brasileiro (BRASIL, 2012). Segundo o Instituto Brasileiro da Cachaça - IBRAC (2013) a capacidade instalada de produção de cachaça no Brasil gira em torno de 1,2 bilhões de litros e estima-se que a capacidade instalada esteja distribuída entre 15 mil estabelecimentos. Seu processo produtivo é composto por algumas etapas, conforme é apresentado na Figura 4 abaixo.

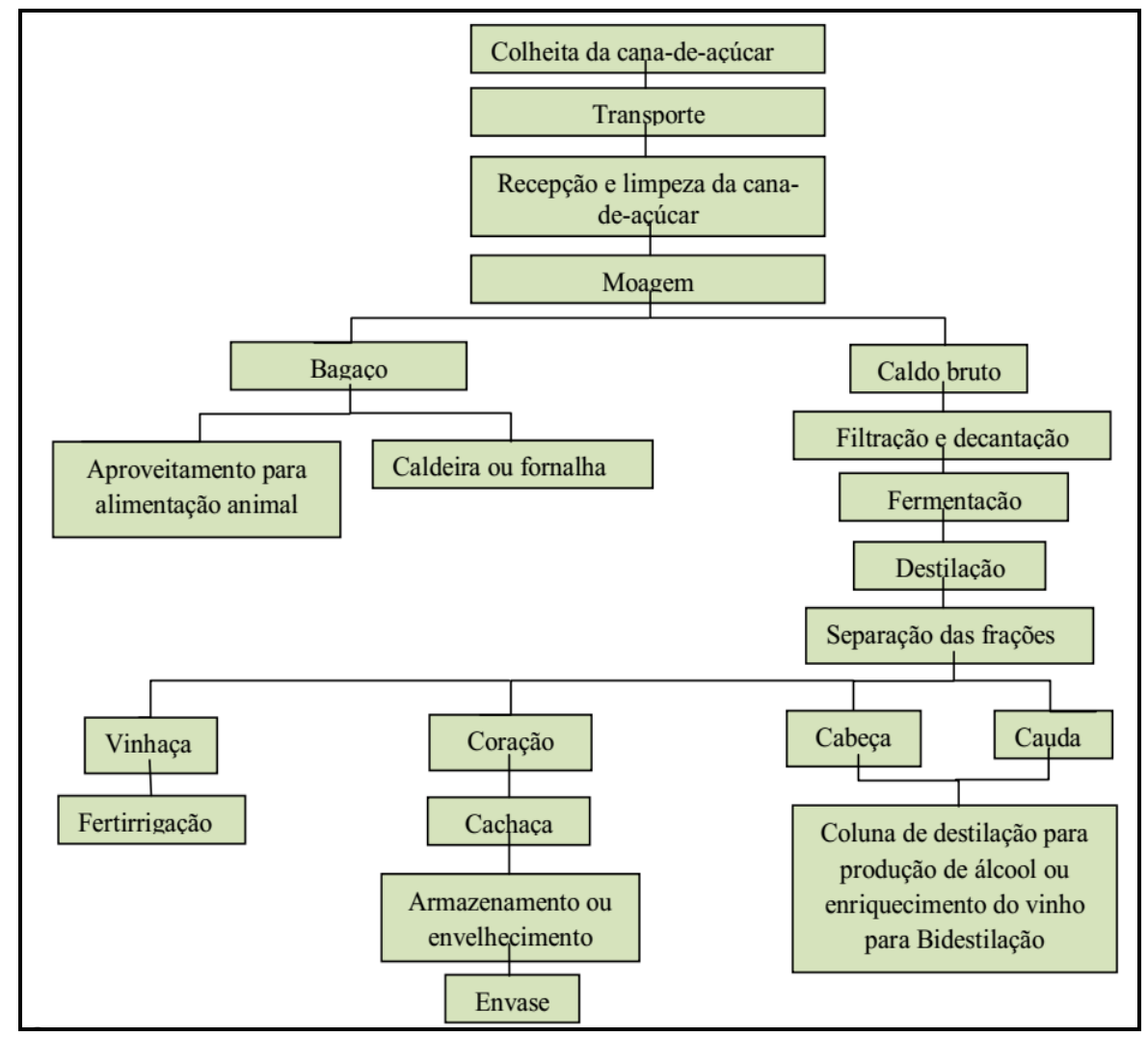

Figura 4 - Etapas do processo produtivo da cachaça.

Fonte: Melo et al. (2012).

A Figura 4 apresenta um panorama geral das etapas do processo produtivo da cachaça. Esta tem fases que causam impacto ao meio ambiente, por isso é importante que as empresas se preocupem em introduzir prática de gestão ambiental e $\mathrm{P}+\mathrm{L}$ em suas atividades produtivas. Assim, considerando a revisão da literatura, observa-se a necessidade da introdução da produção mais limpa nas empresas, objetivando a minimização dos impactos ao meio ambiente e, ao mesmo tempo, a redução dos custos, tornando-se um negócio ambientalmente correto e economicamente viável. A seguir são apresentados os procedimentos metodológicos utilizados para a realização desta pesquisa.

\section{RESULTADOS E DISCUSSÃO}

Nesta seção, são apresentados os resultados da pesquisa alinhados ao objetivo proposto. Inicialmente são apresentadas algumas caraterísticas do objeto estudado e o processo produtivo da cachaça Sanhaçu. 


\subsection{Cachaçaria Sanhaçu: origem e histórico}

A empresa é classificada como de pequeno porte e está localizada no município de Chã Grande/PE, distante cerca de $90 \mathrm{~km}$ de Recife. De cunho familiar, a Sanhaçu fica em uma propriedade de dois hectares na zona rural da família Barreto Silva. A família desde que tomou posse das terras, em 1993, trabalha com agricultura orgânica, seus primeiros produtos eram a produção de frutas e verduras orgânicas, as quais eram comercializadas em feiras da região. Com o passar do tempo - cerca de dez anos - a família começou a pesquisar e conhecer o manejo da cana de açúcar para a produção da cachaça. Segundo a proprietária, seu irmão fez um curso em Minas Gerais para aprender a produzir a boa cachaça, a entrevistada afirmou que "todos os anos ele vai a Minas buscar reciclar e aperfeiçoar o conhecimento para garantirmos a melhor cachaça ao nosso cliente". Seus produtos se diferenciam das demais do mesmo ramo pelo fato de ser um produto totalmente orgânico, já um apelo à questão ambiental. Salienta-se que a Sanhaçu é a primeira cachaça orgânica certificada de Pernambuco.

A escolha do nome Sanhaçu foi uma homenagem a um pássaro que existe em abundância na região e que representa a localidade. Além da cachaça, a empresa produz outros produtos derivados da cana de açúcar e da cachaça, como rapadura, gelatina de cachaça, licores, doces, mel de engenho e açúcar mascavo. Esses produtos, com exceção das cachaças, são comercializados exclusivamente na loja de fábrica, localizada na propriedade da família.

No tocante a cachaça, a Sanhaçu produz três tipos, cuja diferença se dar pelo tipo de tonel de envelhecimento. Segundo o colaborador 1, a cachaça freijó é uma cachaça leve, com pouco sabor, ideal para acompanhar pratos de entrada, como queijo, saladas e peixes. A cachaça de Carvalho tem um sabor amadeirado ideal para pratos condimentados e suculentos. Já a cachaça Umburana tem um sabor adocicado e com sabor de canela, ideal para acompanhar doces.

As cachaças Sanhaçu conquistaram vários prêmios ao longo do tempo. Em 2013 foi Medalha de Ouro na Expocachaça em São Paulo, no mesmo ano ganhou o $1^{\circ}$ lugar na seleção de produtos prêmio da economia pernambucana - Secretaria de Desenvolvimento Econômico do Governo do Estado de PE. Em 2014 conquistou a Medalha de prata no Concurso Mundial de Bruxelas - Bélgica, já em 2015 levou a Medalha de prata no Concurso mundial de destilados de São Francisco - Califórnia - EUA e novamente a Medalha de prata no Concurso Mundial de Bruxelas e a Medalha de duplo ouro do Concurso Mundial de Vinhos e Destilados da China. E não parou por aí, em 2016 foi a melhor cachaça de armazenada em freijó no Ranking da Cúpula da Cachaça, $4^{\circ}$ lugar no Ranking da Cúpula da Cachaça - melhor cachaça armazenada em umburana do Brasil, ganhou ainda a Medalha de prata no Concurso Internacional de Destilados de Berlin e, ainda a Cachaça do Ano - 2016 no mesmo concurso na Alemanha (WEBSITE SANHAÇU, 2017), o que demonstra que a empresa apresenta produtos de qualidade.

Com preocupações não apenas a obter lucro, mas com responsabilidade socioambiental em oferece um produto menos degradante ao meio ambiente e de qualidade, a cachaçaria Sanhaçu se difere dos seus concorrentes pela sua preocupação ao meio ambiente na produção orgânica da cachaça, e por isso consegui melhorar a eficiência do uso de recursos, promover práticas saudáveis em prol do meio ambiente, e minimizar o desperdício de materiais, conforme destacaram Yusup et al. (2014). A seção a seguir apresenta o passo a passo do processo produtivo da cachaça Sanhaçu com base em Melo et al. (2012). 


\subsection{Processo Produtivo da Cachaça Sanhaçu}

A matéria prima utilizada na fabricação da cachaça Sanhaçu é a cana de açúcar que é produzida no canavial da propriedade Barreto Silva. Após a colheita inicia-se a primeira etapa do processo que é a moagem, esta deve ser feita em até 24 horas para garantir a qualidade do caldo da cana de açúcar (Figura 05). Após ser moído, o bagaço da cana é armazenado em uma área para ser utilizado posteriormente como combustão e o caldo segue para a segunda etapa do processo que é a decantação. Na sala de decantação será feito teste para medir o teor de açúcar no caldo de cana. Esse caldo deve ter no mínimo $12 \%$ de teor de açúcar, caso tenha acima basta colocar água para reduzir para $12 \%$.

Depois de atingir o teor de açúcar, o caldo de cana segue para a sala de fermentação, a qual compreende a terceira etapa do processo produtivo. Esta sala possui quatro dornas de inox (Figura 05) que servem para fermentar o caldo com leveduras (fermento) naturais, desenvolvidos a partir da própria cana de açúcar, ou seja, não se utiliza fermentos industriais, por se tratar de um produto orgânico. Essas leveduras são jogadas dentro das dornas juntamente com o caldo de cana, dessa forma o caldo será fermentado para transformação do açúcar que tem no caldo de cana, em álcool. Para que esse fermento trabalhe da melhor forma, a sala de fermentação é mantida com música clássica e instrumental 24 horas por dia, "pois estudos comprovam que com musica clássica seres vivos trabalham melhor, além disso, os funcionários trabalham para deixar essa sala sempre limpa, pouco arejada para propiciar um ambiente agradável para o fermento", afirmou o colaborador 2. Após 24 horas tem-se uma bebida alcoólica conhecida como mosto, a qual apresenta cerca de 12\% de teor alcoólico e quando o fermento não puder mais ser utilizado ele é direcionado para o composto orgânico. Esses processos são representados na Figura 5.

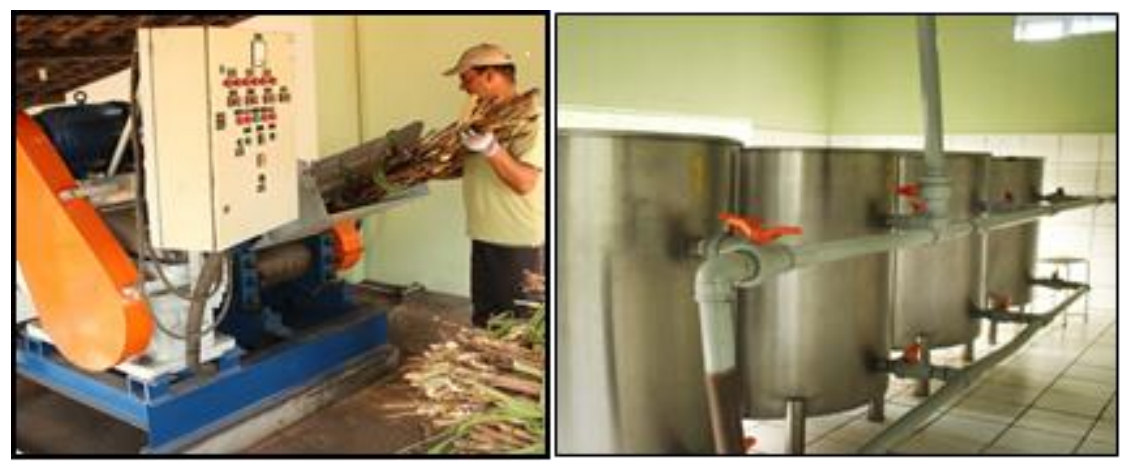

Figura 5 - Processo de moagem da cana de açúcar e dornas fermentação. Fonte: Fonte: Coleta de dados.

Depois dessa etapa, segue-se para a quarta etapa que é a destilação. O mosto é direcionado para os alambiques (Figura 6), que é um destilador que separa os líquidos através do ponto de ebulição de cada substância. Para esse processo a energia térmica usada vem da caldeira (utilizando o bagaço da cana de açúcar), que injeta vapor no alambique. Quando atingir a temperatura de 90 graus célsius o álcool começa a evaporar. O álcool agora está em forma de vapor, é necessário transformar esse vapor em líquido novamente, por meio da condensação. 


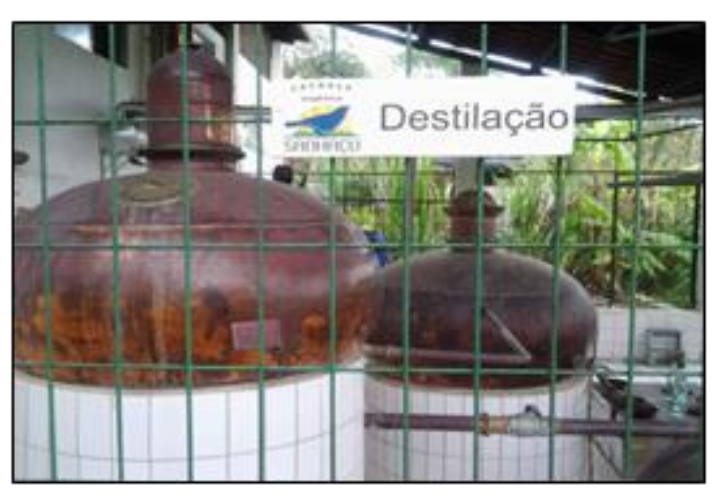

Figura 6 - Sala de destilação da cachaça Sanhaçu. Fonte: Coleta de dados

Dentro do alambique existe um cano em forma de serpente, chamada de serpentina. $\mathrm{O}$ vapor de álcool passa por esse cano, do lado de fora existe água na temperatura ambiente, quando vapor sai do cano existe um choque térmico, fazendo com que o vapor volte para o estado líquido. $\mathrm{O}$ líquido nesse momento do processo já é cachaça. A cachaça passa ainda para outro recipiente por meio de uma serpentina, onde será separada a cachaça boa da cachaça ruim. O processo de destilação é separado em três partes: cabeça, coração e cauda. A composição de cada parte está relacionada com a temperatura de ebulição dos compostos presentes no mosto, sendo o coração a melhor parte. A cabeça compõe os $10 \%$ iniciais da destilação, é rica em aldeídos, metanol e ácidos. A cachaça de cabeça é proibida a comercialização. O coração é composto por cerca de $80 \%$ da destilação, sendo a melhor parte e os $10 \%$ restantes é referente à cauda.

O líquido referente à cabeça e a cauda são colocados em outro alambique que recebe energia térmica em forma de vapor novamente, o álcool que sai desse alambique tem em média 98\% a 99\% de teor alcoólico, é um álcool que serve para abastecer automóveis, ou seja, parte do produto que não é comercializado pela empresa, é utilizado no abastecimento dos veículos da Sanhaçu, "aqui nada se perde, tudo se transforma, cerca de 1000 litros de álcool combustível são gerados por ano e tudo vai para meu carro" afirmou a proprietária entrevistada. O vinhoto que resta é juntado ao bagaço da cana de açúcar formando um composto orgânico, o qual é utilizado para fertilização do canavial e a água dos alambiques é depositada em dois tanques da empresa para ser reaproveita. É importante destacar que parte do bagaço é utilizado para gerar energia na etapa de destilação. Tais atividades rementem a práticas de $\mathrm{P}+\mathrm{L}$, de modo que nenhum rejeito é descartado e sim reaproveitado.

A água depositada nos reservatórios é resfriada com o tempo e depois volta a ser utilizada nos alambiques, se não ocorresse dessa forma, para cada litro de cachaça produzido seria necessários aproximadamente 10 litros de água para resfriar. Percebe-se, portanto, que a empresa se preocupa em não gerar resíduos e reaproveitar ao máximo os insumos utilizados em sua produção. Com a escassez de água atual, este reaproveitamento da água resultado do processo produtivo é uma prática importante e que demostra a preocupação ambiental dos gestores da empresa estudada.

A última etapa do processo é o envelhecimento. Esta etapa define o tipo de cachaça, a partir da madeira que será armazenada por cerca de dois anos. A Sanhaçu tem tonéis de madeira freijó, umburana e carvalho para envelhecer (Figura 7). Cada tipo de madeira tem uma finalidade diferente. Os tonéis de madeira Freijó, madeira típica da Amazônia, transfere pouco gosto, cor e cheiro para a cachaça deixando-a leve. Os tonéis de madeira de Carvalho, madeira importada, 
transfere para a cachaça um sabor amadeirado lembrando o uísque. Já os de Umburana, madeira de várias regiões do Brasil, transfere para a cachaça um sabor mais adocicado.
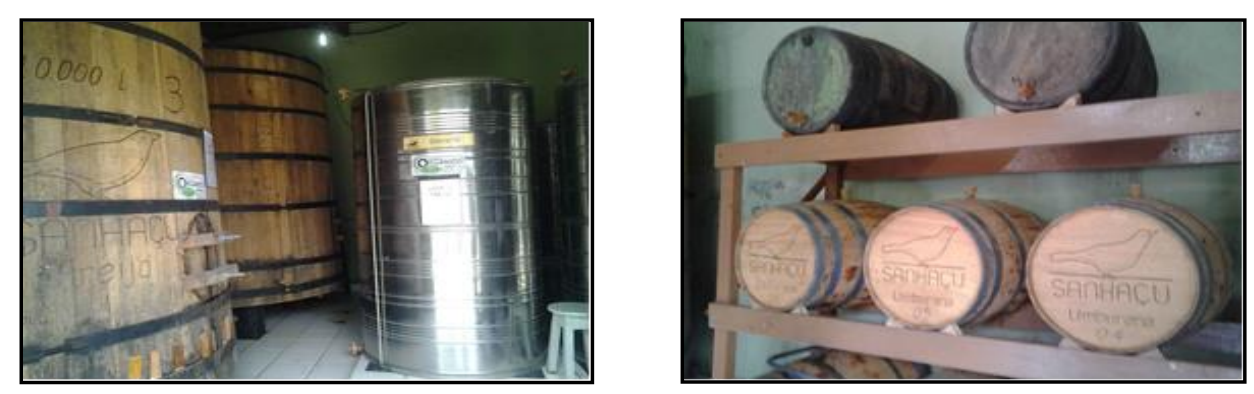

Figura 7 - Tonéis de envelhecimento da cachaça Sanhaçu. Fonte: Coleta de dados (2016).

Quando atingido os dois anos de envelhecimento, caso essa cachaça ainda não tenha sido vendida é transferida para tonéis de inox, que guarda a cachaça, mas não a envelhece. Quando pronta, é retirado duas garrafas de cachaça e enviado para o Instituto de Tecnologia de Pernambuco (ITEP), laboratório que desenvolve uma análise detalhada de todas as substâncias presentes na cachaça. Se os limites estiverem de acordo com os padrões do Ministério da Agricultura, essa cachaça já pode ser comercializada. O engarrafamento é feito todo manual, em uma sala que possui canos finos que puxam a cachaça para as garrafas. O processo de rotulagem também é todo feito manualmente. Após a descrição das etapas do processo produtivo da cachaça orgânica Sanhaçu, a seção a seguir evidencia as práticas de produção mais limpa realizadas pela empresa.

\subsection{Produção Mais Limpa na Sanhaçu}

Uma das práticas de importância para a gestão ambiental é a destinação correta dos resíduos gerados pelas empresas. Resíduo pode ser caracterizado como "tudo aquilo que não é aproveitado nas atividades humanas, podendo ser de origem industrial, comercial ou residencial" (SILVA; MARCIEL; FREITAS, 2013, p.11). O gerenciamento de resíduos gerados considerando o conceito de Produção mais Limpa deve seguir uma hierarquia de preferência, com o intuito de verificar a origem dos resíduos e assim analisar formas de diminuir o problema na fonte. Quando isso não for possível, deve ser estudado formas de reutilizar ou descartar esses resíduos sem prejudicar o meio ambiente.

A seguir é apresentada uma sinopse (Figura 8) do processo produtivo descrito na seção antecedente evidenciando as práticas de produção mais limpa realizadas na cachaçaria Sanhaçu, conforme as etapas do processo produtivo da cachaça apresentadas por Melo et al. (2012). 


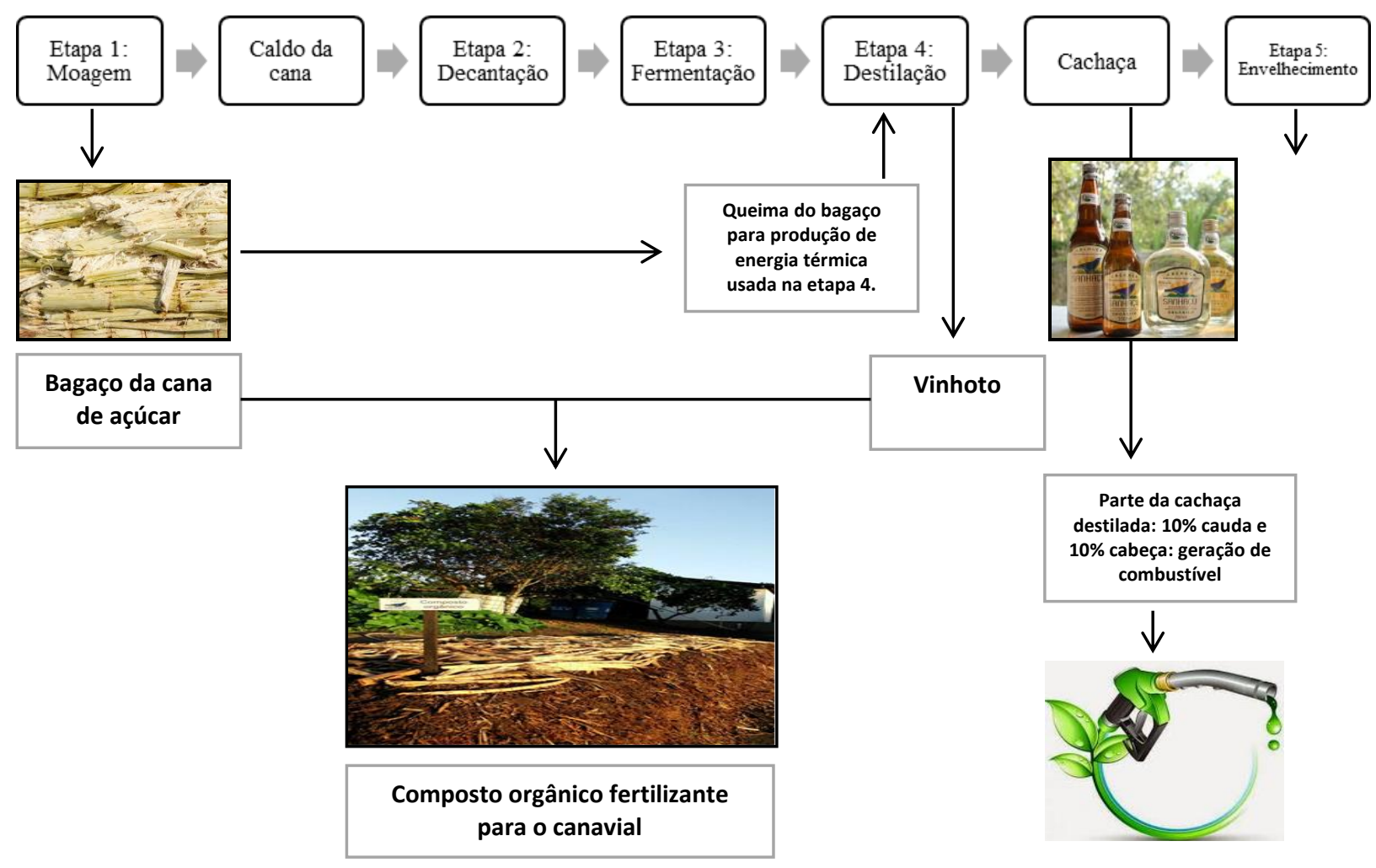

Figura 8 - Sinopse do processo produtivo da cachaça Sanhaçu e as práticas de $\mathbf{P}+\mathbf{L}$ Fonte: Elaborado pelas autoras (2017).

Com base na Figura 8, é observado que a empresa tem um processo produtivo totalmente orgânico e realiza quatro principais práticas de produção mais limpa, quais sejam: reutilização do bagaço da cana de açúcar - geração de energia (fonte de energia renovável) e composição do composto orgânico fertilizante; vinhoto também como parte da composição do composto orgânico fertilizante; reutilização da água dos alambiques para resfriamento da cachaça; parte da cachaça destilada (cauda e cabeça) é utilizada para geração de combustível para abastecimento dos veículos da empresa.

Além disso, é importante destacar que a matéria prima usada para fabricação da cachaça sanhaçu é plantada e colhida em propriedade própria e sem nenhum tipo de agrotóxicos ou substâncias químicas. É um produto resultante de uma matéria prima totalmente limpa e orgânica, por isso que a empresa ganhou o selo de produto orgânico do Ministério da Agricultura. Ressaltase, ainda, que o engenho Sanhaçu é o primeiro do país movido por energia solar em praticamente toda sua produção, são 15 placas fotovoltaicas, conforme ressaltado pelo colaborador 2 .

Considerando os níveis de oportunidade de melhoria baseadas na produção mais limpa proposta pela CNTL (2003) apresentado na Figura 2 (seção 3), e tomando por base as observações feitas pelas pesquisadoras no momento da coleta de dados, tem-se que a Sanhaçu realiza atividades do primeiro nível, como a redução na fonte, através de medidas que visam otimizar o uso de recursos e evitar a geração de poluentes e mesmo aqueles gerados são reintroduzidos ao processo de produção, que é uma prática do segundo nível, apenas o terceiro nível não é realizado, pois não é necessário que a empresa busque medidas de reciclagem de resíduos e efluentes fora da empresa. 
Além destas práticas, outras práticas de gestão ambiental puderam ser observadas na empresa como a existência de uma horta orgânica, que antes da cachaça, era o produto comercializado pela família em feiras da região. Atualmente as frutas, legumes e verduras provenientes da horta orgânica (Figura 9) servem para consumo próprio da família, e alguns poucos produtos ainda são comercializados na loja da fábrica, como pimenta rosa, alguns doces de frutas e até mesmo a própria fruta.

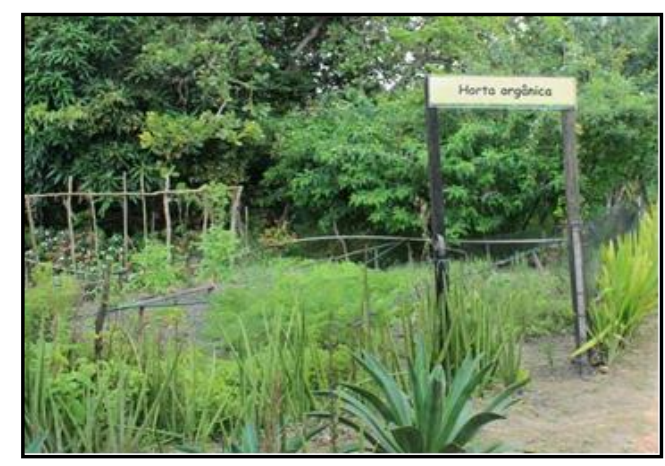

Figura 9 - Horta orgânica do território da família Barreto. Fonte: Coleta de dados.

Outra prática realizada é o agroflorestamento que busca produzir alimentos no ambiente de floresta nativa. O reflorestamento na propriedade da família é resultado de 15 anos de trabalho, após esse reflorestamento a fauna voltou a viver na região, podendo encontrar uma variedade de animais na região, além do pássaro Sanhaçu, que voltou a viver na região e deu nome a empresa. Além disso, a empresa Sanhaçu utiliza energias renováveis na sua produção. A energia eólica, proveniente dos ventos forte da região é utilizada para bombear água resfriada para os alambiques. A empresa possui dois painéis de energia solar que serve para o uso doméstico dos familiares. E o bagaço da cana de açúcar também serve de energia para alimentar a caldeira, todas fontes de energias renováveis.

Destarte, considera-se que a Cachaçaria Sanhaçu apresenta práticas de produção mais limpa que caracterizam seu processo produtivo como limpo e orgânico, além de outras práticas de gestão ambiental que podem caracterizar uma empresa ambientalmente responsável. Desse modo a empresa está em acordo com a definição da UNEP que diz que a P+L é a aplicação contínua de uma estratégia ambiental preventiva integrada aos processos, produtos e serviços para aumentar a eficiência global, e reduzir os riscos para os seres humanos e o meio ambiente (UNEP, 2006). Destacamos que a empresa apresenta práticas de $\mathrm{P}+\mathrm{L}$ em todo seu processo produtivo, desde da extração da matéria prima até a finalização do seu processo, além de práticas como a horta orgânica, o agroreflorestamento, uso de energia solar e eólica, assim como o não uso de agrotóxicos.

\section{CONCLUSÃO}

A partir do atendimento do objetivo de analisar as práticas de produção mais limpa que são adotadas pela cachaçaria sanhaçu no seu processo produtivo, constatou-se que a empresa realiza práticas de $\mathrm{P}+\mathrm{L}$ e gestão ambiental em seu processo produtivo e gestão, é culturalmente uma empresa preocupada com a preservação ambiental. 
A pesquisa revelou que a cachaçaria Sanhaçu apresenta um processo produtivo orgânico, e que grande parte dos resíduos gerados são reintroduzidos ao processo de produção ou reutilizados, como o combustível que abastece os carros da empresa. Outro ponto importante que deve ser destacado é que a empresa detém todo poder de produção sem depender de fornecedores. Isso ocorre porque a matéria prima utilizada, a cana de açúcar, é cultivada em propriedade privada da família. Isso permite que a cachaçaria Sanhaçu possua total controle de qualidade dos produtos fornecidos.

Em relação à adoção do programa de Produção mais Limpa, a pesquisa mostrou que não é necessário ser uma empresa de grande porte para obter sucessos com as estratégias de $\mathrm{P}+\mathrm{L}$. O importante nessa questão, e que torna a Sanhaçu diferente das empresas do mesmo ramo, é o fato de que os gestores entendem a importância da implementação da Produção mais Limpa e buscaram cursos para aperfeiçoamento. Com base na coleta de dados, é possível afirmar que a empresa adotou as práticas de $\mathrm{P}+\mathrm{L}$ e gestão ambiental não por pressão dos seus stakeholders, mas por interesse dos próprios gestores da organização em oferecer um produto que fosse menos degradante ao meio ambiente e, ao mesmo tempo, de qualidade, embora foi perceptível o aumento dos custos e, por conseguinte o preço final do produto ${ }^{1}$.

Com a aplicação da P+L a empresa realiza a plantação da cana-de-açúcar sem utilização de agrotóxicos, corte da cana feito manual. A moagem da cana é realizada em máquina industrial apropriada e seu bagaço é direcionado para a caldeira, para entrar em combustão e produzir energia térmica, e o restante não utilizado é depositado no composto orgânico. $O$ fermento utilizado na produção também é produzido pela empresa, através do pó encontrado nos nós da cana de açúcar. No processo de destilação, toda a água utilizada é reaproveitada, sendo transportada por meio de energia eólica. Nesse processo existe o vinhoto como resíduo, que é depositado no composto orgânico. Esse composto orgânico será utilizado como adubo para o canavial. O álcool proveniente da cachaça de cabeça e cauda é transformado em álcool combustível. A Sanhaçu é uma empresa que vende crédito de carbono no mercado, isso possibilita que o pouco que a empresa produz de emissão no meio ambiente seja compensado pelo trabalho de reflorestamento na propriedade e ainda comercializa créditos para outras empresas.

Todas essas práticas permitem que a Sanhaçu minimize seus impactos ao meio ambiente e reduza seus gastos no processo produtivo, o que possibilita a empresa produzir com qualidade respeitando o meio ambiente. Com base no que sugerem Bocken et al. (2014), podemos considerar a Cachaçaria Sanhaçu um modelo de negócio sustentável por alinhar os interesses empresariais com a preservação do meio ambiente. Tal forma de gestão está já resultou em diversos prêmios desde 2013. Salienta-se que o sítio Barreto Silva está aberto à visitação pública diariamente e começa a se consolidar também como atração turística. Este estudo apresenta contribuições tanto a nível acadêmico, a partir da realização de uma pesquisa científica que trouxe à tona as abordagens teóricas de produção mais limpa, como para a sociedade por meio de um estudo que apresentou que é possível que empresas realizem suas atividades produtivas minimizando os seus efeitos ao meio ambiente e a sociedade, oferecendo produtos de qualidade e de menor impactos socioambientais.

Recomenda-se para pesquisas futuras a realização de estudos que tragam à tona a dimensão social da sustentabilidade, haja vista que não é dever da empresa apenas a preocupação ambiental, mas também a social, já que suas atividades impactam de forma direta a sociedade. Outro estudo

\footnotetext{
${ }^{1}$ Não é o objetivo específico da pesquisa a análise de custos e valor final do produto comercializado. Com base na coleta de dados primários não é possível apresentar detalhes percentuais de quanto o custo e preço foram aumentados.
} 
que é sugerido é a realização de uma pesquisa mais ampla envolvendo a cadeia de suprimentos da cachaçaria Sanhaçu.

\section{REFERENCIAS}

AGENDA 2030. Transformando Nosso Mundo: A agenda para o desenvolvimento Sustentável. Organização das Nações Unidas. Nova Iorque, 2015.

BARBIERI, J. C. Gestão ambiental empresarial: conceitos, modelos e instrumentos. $4^{a}$ ed. São Paulo: Saraiva, 2016.

BARDIN, L. Análise de Conteúdo. Lisboa, Portugal; Edições 70, LDA, 2011.

BATISTA, I. R. M.; GIESTA, L. C.; LEITE, Y. V. P. Ações de gestão ambiental: um estudo na cadeia ceramista do Vale do Assú/RN. In: Anais do Simpósio de Administração da Produção, Logística e Operações Internacionais (SIMPOI), FGV. São Paulo, 2013.

BOCKEN, N. M. P.; SHORT, S. W.; RANA, P.; EVANS, S. A literature and practice review to develop sustainable business model archetypes. Journal of Cleaner Production, v. 65, n. 15, p. 42-56, 2014.

BRASIL. Ministério da Saúde. ANVISA - Agência Nacional de Vigilância Sanitária. Decreto $\mathrm{n}^{\circ} 6871$ de 4 de junho de 2009. Regulamenta a Lei $\mathrm{n}^{\mathrm{o}} 8918$ de 14 de julho de 1994, que dispõe sobre a padronização, a classificação, o registro, a inspeção, a padronização e a fiscalização de bebidas. D.O.U. - Diário Oficial da União, Poder Executivo, Brasília, DF, 5 jun. 2009. Seção 1, p. 20.

Receita Federal. Decreto $\mathrm{n}^{\circ} 4.072$, de 03 de janeiro de 2002. Brasília, 2002. Disponível em: <http://www.receita.fazenda.gov.br/Legislacao/Decretos/2002/dec4072.htm〉. Acesso: Fev. de 2017.

CACHAÇA COM NOTÍCIA. Atitude Consciente. Jornal Informativo da Associação Mineira dos Produtores de Cachaça de Qualidade. AMPAQ, 2015.

CACHAÇA SANHAÇU. Disponível em: < http://www.sanhacu.com.br >. Acesso em Fev. de 2017.

CENTRO NACIONAL DE TECNOLOGIAS LIMPAS - CNTL. Meio ambiente e a pequena e microempresa: módulo 1 - Curso de Formação de Consultores em Produção Mais Limpa. Porto Alegre: CNTL, 2003. 73 p.

CRESWELL, J. W. Projeto de pesquisa: métodos qualitativo, quantitativo e misto. 3 ed. Porto Alegre: Artmed, 2010.

DENZIN, N. K.; LINCOLN, Y. S. O planejamento da pesquisa qualitativa: teorias e abordagens. 2. ed. Porto Alegre: Artmed, 2006.

DIAS, R. Gestão Ambiental: Responsabilidade social e sustentabilidade. 2. ed. São Paulo: Atlas, 2011.

FREITAS, H.; JANISSEK, R. Análise Léxica e Análise de Conteúdo: técnicas complementares, seqüências e recorrentes para análise de dados qualitativos. Porto Alegre. Sphinx-Sagra (distrib.). 2000, 176 p.

GASKELL, G. Entrevistas individuais e grupais. In: BAUER, M. W.; GASKELL, G. (Org.). Pesquisa qualitativa com texto, imagem e som: um manual prático. Petrópolis: Vozes, 2002. p. 64-89.

GLAVIC, P.; LUKMAN, R. Review of sustainability terms and their definitions. Journal of Cleaner Production, v. 15, p. 1875-1885, 2007.

GREENPEACE. What is Clean Production? 2001. Disponível em: < http://teclim.ufba.br/jsf/producaol/greenpeace\%20cpb.PDF>. Acesso em: Fev. de 2017.

INSTITUTO BRASILEIRO DA CACHAÇA - IBRAC. 2013. Disponível em: < http://www.ibrac.net/>. Acesso em: Jan. 2017.

JABBOUR, C. J. C. Non-linear path ways of corporate environmental management: a survey of ISO 14001- certfed companies in Brazil. Journal of Cleaner Producton, v. 18, pp. 1222-1225, 2010.

MAGNAGO, P. F. Produção mais Limpa: Uma análise de seus métodos e formas de implementação. 2013. 79 f. Monografia (Especialização) - Curso de Engenharia Ambiental, Universidade Federal do Rio Grande do Sul, Porto Alegre, 2013. 
MELO, W. F; PEREIRA, R. A.; FILHO, R. S.; ALMEIDA, J. S.; NASCIMENTO, K. N. F. Cadeia Produtiva da Cachaça Triunfo: Um Estudo de Caso. Revista Verde de Agroecologia e Desenvolvimento Sustentável. Mossoró-RN, V. 7, n. 3, p. 41-45, jul-set, 2012.

PEIXE, B. C. S; et.al. Evolução do sistema de gestão ambiental das empresas no Brasil: Um estudo exploratório das certificações. In: Anais do $3^{\circ}$ Internation Workshop Advances in Cleaner Production. 2011.

PIMENTA, H. C. D.; GOUVINHAS, R. P. A produção mais limpa como ferramenta da sustentabilidade empresarial: um estudo no estado do Rio Grande do Norte. Produção, v. 22, n. 3, p. 462-476, maio/ago. 2012.

REVISTA GAZETA. Sanhaçu - Cachaça orgânica e Produtos agroecológicos. Pernambuco - Brasil. Disponível em: <http://www.sanhacu.com.br/cachaca-sanhacu-revista-gazeta-cutural/. Acesso em: Fev. de 2017.

SANTANA, M. S. Aplicação dos princípios de Produção mais Limpa (P+L) e Ecodesign na redução do consumo de energia elétrica. Estudo de caso: SATC, Criciúma - SC. Trabalho de Conclusão de Curso. Universidade do Extremo Sul Catarinense (UNESC). Curso de Engenharia de Produção. 72p. 2009.

SANTOS, J. G.; CARNEIRO, V. C. V.; RAMALHO, A. M. C. Sustentabilidade e produção mais limpa: um estudo sobre as implicações na vantagem competitiva empresarial. Revista Metropolitana de Sustentabilidade - RMS, São Paulo, v. 5, n. 2, p. 34-48, maio/ago., 2015.

SCHALTEGGER, S.; LÜDEKE-FREUND, F.; HANSEN, E. G. Business cases for sustainability: the role of business model innovation for corporate sustainability. International Journal of Innovation and Sustainable Development, v. 6, n. 2, p. 95-119, 2012.

SEIFFERT, M. E. B. Gestão Ambiental: Instrumentos, esferas de ação e educação ambiental. São Paulo: Atlas, 2010.

SILVA, M. C. V. G.; MACIEL, D. dos S. C.; FREITAS, L. S. de. Avaliação do processo produtivo da cachaça de alambique do engenho Pé de Serra à luz da Produção mais Limpa. In: SEMINÁRIO EM ADMINISTRAÇÃO, 16., 2013, São Paulo. Anais... .São Paulo: Semead, 2013. p. 1 - 16.

SILVA, E. L. A. et al. Contribuições da produção mais limpa, ecoeficiência e sustentabilidade como alternativas de agregação de valor para uma cooperativa de materiais reciclados. Desafio Online v.5, n.2, art.5 Mai./Ago., pp. 242-260, 2017.

UNITED NATIONS ENVIRONMENT PROGRAMME - UNEP. Environmental agreements and cleaner production. 2006. Disponível em: http://www.unep.fr/scp/publications/details.asp?id=DTI/0833/PA Acesso em: Fev. de 2017.

VAN BERKEL, R. Cleaner Producton and Eco-efciency initatves in Western Australia. Journal of Cleaner Producton. v. 15, pp. 741-755, 2007.

VENANZI, D. C.; MORIS, V. A. S. Produção mais Limpa: estudo sobre as empresas fabricantes de componentes automotivos localizadas na cidade de Sorocaba-SP. GEPROS. Gestão da Produção, Operações e Sistemas, Bauru, Ano $8, \mathrm{n}^{\circ} 1$, jan-mar/2013, p. 119-132.

YIN, R. K. Estudo de Caso: planejamento e métodos. $5^{\mathrm{a}}$ ed. Porto Alegre: Bookman, 2015.

YONG, J. Y.; KLEMEŠ, J. J.; VARBANOV, P. S.; HUISINGH, D. Cleaner energy for cleaner production: modelling, simulation, optimisation and waste management. Journal of Cleaner Production, v. 111, p.1-16, 2016.

YUSUP, M. Z.; WAN MAHMOOD, W. H.; SALLEH, M. R.; RAHMAN, MUHAMAD, M. R. The Influence Factor for the Successful Implementation of Cleaner Production: A Review. Journal Teknologi, v. 67, n.1, 2014, p. 89-97. 